\title{
Wagner verstärkt Kleb- und Dichtaktivitäten
}

$D^{a}$ as auf dem Gebiet der industriellen Oberflächentechnik aktive Unternehmen Wagner Industrial Solutions verstärkt seinen Geschäftsbereich „Kleben \& Dichten“. Everton Francisco übernahm im Februar die Leitung dieses Geschäftsfeldes, zu dem auch die Reinhardt-Technik GmbH, Kierspe, gehört. Francisco verfügt über weitreichende internationale Erfahrungen als Geschäftsführer und war unter anderem in Vertrieb, Produktentwicklung, Application-Engineering, Qualitäts- und Prozessmanagement tätig. Der studierte Maschinenbauingenieur mit betriebswirtschaftlichem Master-Abschluss füllte verschiedene Positio- nen bei der Stabilus-Gruppe in Brasilien, Mexico und Deutschland aus und arbeitete zuletzt als Geschäftsführer für Stabilus in Spanien. In seiner neuen Tätigkeit wird er das Geschäftsfeld „Kleben \& Dichten“ weiter ausbauen. „Mit dem Eintritt in das Segment Kleben und Dichten hat die Wagner-Gruppe eine hervorragende Möglichkeit genutzt, ihr Produkt-Portfolio zu diversifizieren und sich für die Dynamik des globalen Markts gestärkt aufzustellen“, so Everton Francisco.

Everton Francisco, neuer Leiter Geschäftsbereichs „Kleben \& Dichten“ bei Wagner Industrial Solutions

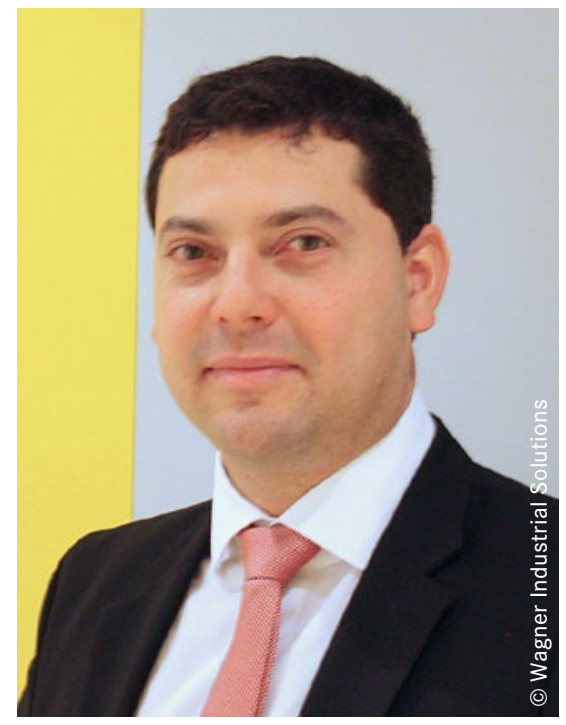

\section{Industriekreis „Kleben im Automobilbau“}

Am 5. Juni 2013 veranstaltet die Bayern Innovativ GmbH im Rahmen des Netzwerkes BAIKA und des Clusters Automotive in Zusammenarbeit mit dem Fraunhofer IFAM das 12. Kooperationsforum „Kleben im Automobilbau“.

$\mathrm{D}$ urch kontinuierliche Weiterentwicklungen ist die Klebtechnik zu einer der zukunftsorientierten Verbindungstechnologien für das Multimaterialdesign im Automobilbau geworden. Neun Prozent der gesamten jährlichen Klebstoffproduktion entfallen auf die Fahrzeugbranche. Ein Auto enthält heute rund 15 bis $18 \mathrm{~kg}$ Klebstoff - Tendenz steigend.

Der Automobilbau ist somit bekanntlich ein wesentlicher Treiber für klebtechnische Innovationen auch über die Branchengrenzen hinweg. Die Klebtechnik bietet hierzu enorme Potenziale in ökonomischer wie ökologischer Hinsicht. Mit der Weiterentwicklung von Klebstoffen und Produktionstechnologien lassen sich Prozesse optimieren, Taktzeiten verkürzen, Fahrzeuggewichte reduzieren und Ressourcen einsparen.

Vor diesem Hintergrund findet bereits zum 12. Mal in Nürnberg das Kooperationsforum „Kleben im Automo-

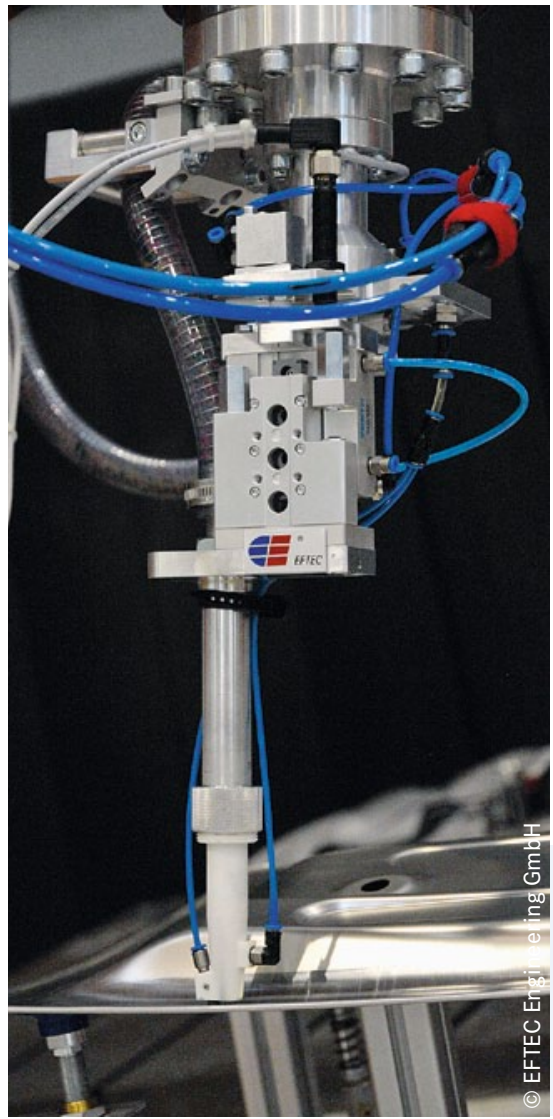

bilbau“ statt. Automobilhersteller und -zulieferer, Forschungsinstitute sowie Klebstoffproduzenten stellen auch in diesem Jahr innovative Produktentwicklungen und aktuelle Lösungsansätze vor - z.B. Optimierung von Taktzeiten durch die gezielte Einstellung der Reaktivität von Klebstoffen sowie automatisierte Applikations- und Bearbeitungstechnologien. Beispielhafte Themen sind ferner sichere und robuste Prozesse beim CFK-Kleben, der automatisierte Klebstoffauftrag im Karosseriebau und Haftklebstoffe auf Basis nachwachsender Rohstoffe.

Weitere Infos: www.bayern-innovativ.de

Mit der Weiterentwicklung von Klebstoffen und Produktionstechnologien lassen sich Prozesse optimieren, Taktzeiten verkürzen, Fahrzeuggewichte reduzieren und Ressourcen einsparen. 